\title{
A INSERÇÃO DA BIOPOLÍTICA NO DISCURSO DOS DIREITOS HUMANOS: A TRANSPOSIÇÃO DA VIDA DE DIREITO DO HOMEM INALIENÁVEL À OBJETO MATÁVEL
}

\author{
Rebeca Fernandes Dias*
}

\begin{abstract}
RESUMO
O artigo pretende mostrar: como o direito à vida e a idéia de sua sacralidade e proteção absoluta, como bem jurídico fundamental, direito humano universal, corresponde a uma construção histórica; que esta construção histórica teve méritos humanitários, mas, que todo este discurso de supervalorização da vida humana carrega uma forte dose de poder e dominação sobre o ser humano enquanto sujeito de direitos - trata-se da biopolítica. A idéia é trabalhar com um autor do jusnaturalismo e liberalismo do século XVII ou XVIII, como Locke, e demonstrar como o discurso dos direitos naturais transcorreu deste período ao século XIX em que a biopolítica tornou-se evidente. Como, então, a biopolítica ingressa na lógica da proteção dos direitos humanos que tiveram sua origem na teoria dos direitos naturais. O objetivo será, então, apontar, dentro da própria filosofia ocidental, como o valor vida pode ser relativizado pelo mesmo discurso que a eleva a valor fundamental e direito humano inalienável, ou seja, demonstrar que o fundamento de sua proteção absoluta e de sua relativização imbrica no mesmo ponto: a biopolítica.
\end{abstract}

Palavras-chave: vida; direitos humanos; biopolítica; sujeito de direito; poder.

Sumário: INTRODUÇÃO; 1 JUSNATURALISMO MODERNO E A AFIRMAÇÃO HISTÓRICA DOS DIREITOS HUMANOS: DO HOMEM AO CIDADÃO; 2 A INSERÇÃO DA BIOPOLÍTICA NA LÓGICA DOS DIREITOS HUMANOS; 3 A REDUÇÃO DOS DIREITOS HUMANOS AOS DIREITOS DO CIDADÃO: DE CIDADÃO À VIDA NUA; CONCLUSÃO. REFERÊNCIAS.

\footnotetext{
* Mestranda em Relações Sociais na UFPR. Endereço eletrônico: rezinhafd@hotmail.com
} 
"[...] é chegado o momento de cessar de ver as declarações de direitos como proclamações gratuitas de valores eternos metajurídicos, que tendem (na verdade sem muito sucesso) a vincular o legislador ao respeito pelos princípios éticos eternos, para então considerálas de acordo com aquela que é a sua função histórica real na formação do moderno Estadonação".

Giorgio Agambem

\section{INTRODUÇÃO}

A construção histórica dos direitos humanos teve uma relevância e afirmação acentuada com as teorias jusnaturalistas, a partir do século XVII. Nesta fase histórica, já considerada modernidade, a questão do homem, a sua essência e a sua natureza tornaram-se centrais.

A idéia de Estado e de direitos do homem, sendo o primeiro, a partir da visão jusnaturalista moderna, uma instituição artificialmente criada para a proteção destes direitos, decorreram exatamente dos questionamentos a respeito da natureza humana e do princípio da autoconservação do homem, princípio este presente em toda a filosofia jusnaturalista moderna.

A individualização do homem, ou seja, a tomada de uma perspectiva que visualiza o sujeito como algo autônomo e independente da comunidade e do corpo social - contrastante, portanto, com a lógica medieval orgânico-corporativista - e, a afirmação de direitos inerentes ao homem, decorrentes de sua própria natureza e dignidade humana são os alicerces embrionários que dão origem à filosofia política moderna, a partir da qual surge a sociedade política, o poder soberano e o direito positivo declarado, ou seja, a Lei.

O percurso histórico que transcorreu da fundamentação filosófica às revoluções, como a independência americana, em 1776 e, a Revolução Francesa, em 1789, foi marcado por muito sangue e muita luta, e sem dúvida alguma a proteção incondicional e constitucional de nossas vidas hoje é conseqüência de um passado 
sangrento.

Não obstante os méritos humanitários conquistados pelo ocidente a partir do discurso dos direitos humanos, no sentido de proteção do homem e de sua vida, a história mostra, principalmente a partir do século XIX, que todo este discurso de supervalorização da vida humana carrega uma forte dose de poder e dominação sobre o ser humano enquanto sujeito de direitos, portanto, enquanto cidadão.

A institucionalização do Estado e da Lei, com a declaração dos direitos do homem e do cidadão transformaram, justamente, o homem em cidadão e esta passagem, embora marcada pela afirmação e conquista de direitos, liberdades e garantias, também simbolizou a inserção de um novo poder sobre o sujeito e sua vida: o biopoder, a biopolítica.

A primeira metade do século XX, com as duas grandes guerras e a questão dos refugiados e apátridas, permitiu a humanidade testemunhar a flagrante insuficiência do discurso da universalidade dos direitos humanos, dentre eles o direito à vida. Como pôde o homem cometer tantas atrocidades contra a própria humanidade, mesmo após todo o percurso histórico de afirmação dos direitos do homem? Como pôde a inalienabilidade e inviolabilidade da vida tornar-se tão relativizada?

A proposta do presente artigo será demonstrar, então, que o fundamento da proteção absoluta da vida do homem, como um direito humano inalienável e inviolável, e a sua relativização, imbricam no mesmo ponto: a biopolítica.

\section{O JUSNATURALISMO MODERNO E A AFIRMAÇÃO HISTÓRICA DOS DIREITOS HUMANOS: DO HOMEM AO CIDADÃO}

O jusnaturalismo moderno é o responsável pela idéia de que o homem, por sua natureza humana, é dotado de direitos que ninguém pode subtrair, e que ele mesmo 
não pode alienar. Um dos pais deste pensamento foi John Locke. ${ }^{1}$

Para Locke, ${ }^{2}$ os homens, em sua condição natural, são dotados de absoluta liberdade e igualdade, na qual ninguém tem ou pode mais que os outros. Assim, a condição natural dos homens é:

[...] um estado em que eles sejam absolutamente livres para decidir suas ações, dispor de seus bens e de suas pessoas como bem entenderem, dentro dos limites do direito natural, sem pedir a autorização de nenhum outro homem nem depender de sua vontade [...] Um estado, também, de igualdade, onde a reciprocidade determina todo o poder e toda a competência, ninguém tendo mais que os outros $[\ldots . .]^{3}$

Não obstante este estado de liberdade e independência, o estado de natureza não corresponde a um estado de permissividade, uma vez que ninguém pode lesar o outro em sua vida, saúde ou liberdade. O princípio da autoconservação é reinante, no sentido de que cada um é obrigado a conservar a si próprio e velar para a conservação do restante da humanidade.

O Direito Natural $^{4}$ ordena a paz entre os homens e a conservação da humanidade - o estado de natureza é regido pela lei da natureza. Neste estado todos têm poder sobre todos, ou seja, todos podem punir aquele que agiu contra a lei natural: "[...] todo homem pode reivindicar seu direito de preservar a humanidade, punindo ou, se necessário, destruindo as coisas que lhe são nocivas". ${ }^{5}$

Em razão de no estado de natureza todo homem poder ser juiz em causa

${ }^{1}$ In BOBBIO, Norberto. A era dos direitos. Trad. Carlos Nelson Coutinho. Rio de Janeiro: Campus, 1992, p. 28.

${ }^{2} \mathrm{O}$ presente artigo optou trabalhar especificamente com a teoria de Locke, mas ressalta-se que qualquer jusnaturalista, desde Hobbes até Rousseau, poderiam servir para a construção da idéia na qual pretende-se chegar, na medida em que a essência da idéia jusnaturalista é a mesma em todos os autores, ainda que certos elementos de suas teorias se diversifiquem.

${ }^{3}$ LOCKE, John. Segundo tratado sobre o governo civil: ensaio sobre a origem, os limites e os fins verdadeiros do governo civil. 3. ed. Rio de Janeiro: Vozes, 1994, p. 83.

${ }^{4}$ Para Locke o Direito Natural decorre do poder e da vontade de Deus e é apreendido pela razão humana. Racionalismo e voluntarismo tendem a se encontrar. Por ser um direito divino é, portanto, universalmente vinculante.

$$
{ }^{5} \text { Ibid., p. } 86 .
$$




\section{A INSERÇÃO DA BIOPOLÍTICA NO DISCURSO DOS DIREITOS HUMANOS: A TRANSPOSIÇÃO DA VIDA DE DIREITO DO HOMEM INALIENÁVEL À OBJETO MATÁVEL}

própria e das inconveniências que isto pode acarretar, faz-se necessária a instituição de um governo, o governo civil.

A formação do corpo político advém, então, da necessidade de manutenção e garantia da liberdade e igualdade características essenciais do estado de natureza, que o homem é incapaz de assegurar sozinho:

[...] as leis da natureza obrigam os homens de maneira absoluta, porque eles são homens [...] mas como somos incapazes por nós mesmos de buscar uma quantidade suficiente de objetos necessários ao gênero de vida que nossa natureza deseja, uma vida à medida da dignidade do homem, e assim suprir os defeitos e as imperfeições que nos são inerentes quando vivemos sozinhos e solitários, somos naturalmente induzidos a buscar a comunhão com os outros e sua companhia; esta foi a causa dos homens terem se unido em sociedades políticas. ${ }^{6}$

A formação deste corpo político se dá por meio de um contrato, no qual as pessoas manifestam o seu consentimento em renunciar seu próprio direito-poder a favor da concentração da figura do soberano.

Todavia, não é o contrato o fundamento do poder soberano, mas sim a lei natural, sendo aquele apenas um instrumento para a formação da obrigação política.

Na idéia de Locke, portanto, o homem já nasce, por sua própria condição humana, dotado de todos os direitos e privilégios da lei da natureza, todavia no estado de natureza que é marcado pela insegurança e imprevisibilidade, o gozo destes direitos é precário. Para assegurar os direitos que lhe são inerentes, os homens criam a sociedade política (princípio da autoconservação) renunciando a certos poderes, como o de ser juiz de qualquer outro homem, tornando a comunidade o verdadeiro árbitro.

Locke afirma a instituição da sociedade civil para a salvaguarda da vida, da liberdade e dos bens, o que, genericamente, vem a intitular pelo nome geral de propriedade. $^{7}$ Portanto, a preservação da propriedade é a principal finalidade da instituição do governo e da sociedade.

\footnotetext{
${ }^{6}$ Ibid., p. 89-90.

${ }^{7}$ Propriedade para Locke tem um significado essencial, pois indica a esfera de subjetividade do sujeito, a sua liberdade de ação e a condição para a sua autoconservação.
} 
Os indivíduos que. segundo Locke. existem independentemente da sociedade, reúnem-se em um corpo único dotado de um sistema jurídico e judiciário com competência de decidir e punir aqueles que infringem contra a propriedade do outro.

A passagem, então, do estado de natureza para a comunidade civil se dá com a instituição de um juiz na terra com autoridade para decidir as controvérsias e punir. E, este juiz para Locke é, exatamente, o legislativo.

O direito para Locke é uma expressão da liberdade do sujeito, ligado à idéia de ação livre e autoconservativa. O sujeito é visto, então, como um sujeito de direitos, sendo estes tidos como liberdades decorrentes do direito natural.

Estabelecido um governo público e concedida a autoridade àquele que o representar (o soberano), este terá a legitimidade para legislar e governar proporcionando assim a paz, a tranqüilidade e o bem-estar.

Cabe lembrar, todavia, que para Locke, tanto o soberano quanto os súditos estão, na mesma medida, submetidos à lei da natureza, pois para ele, nenhum homem na sociedade civil pode estar imune às leis naturais. Ao soberano estas leis se impõem determinando os limites do poder e para os súditos obrigando-os à obediência.

Com o jusnaturalismo de Locke e de tantos outros, como Hobbes, Rousseau, por exemplo, (ressaltando-se as diferenças das teorias de cada um), percebe-se a teorização da individualização do sujeito, ou seja, a visualização do homem não apenas como uma parte de um organismo maior (mentalidade medieval), mas como um ente autônomo, dotado de direitos inerentes à sua condição humana - a questão antropológica que se preocupa com a essência humana é notável. Desta individualização do homem parte-se para pensar a necessidade das relações intersubjetivas entre os homens, seja este pensamento fundamentado pela conflituosidade hobbesiana ou pela insegurança lokciana. Por necessidade ou tendência natural do homem surge a sociedade civil e a comunidade política. A condição humana é transmutada para uma condição de súdito e mais tarde para a condição de cidadão, e esta transmutação corresponde exatamente ao percurso histórico de afirmação dos direitos humanos em conseqüência das revoluções e 


\section{A INSERÇÃO DA BIOPOLÍTICA NO DISCURSO DOS DIREITOS HUMANOS: A TRANSPOSIÇÃO DA VIDA DE DIREITO DO HOMEM INALIENÁVEL À OBJETO MATÁVEL}

declarações de direitos delas decorrentes.

A promulgação da Lei de Habeas Corpus, na Inglaterra, deu início a um processo de afirmações dos direitos do homem declarados teoricamente pela filosofia jusnaturalista. Como afirma Fabio Konder Comparato: "A importância histórica do habeas-corpus, tal como regulado pela lei inglesa de 1679, consistiu no fato de que essa garantia judicial, criada para proteger a liberdade de locomoção, tornou-se a matriz de todas as que vieram a ser criadas posteriormente, para a proteção de outras liberdades fundamentais". 8

Esta lei foi seguida pela Declaração do Bill of Rights, em 1689, documento que instituiu a separação de poderes, encarregando o Parlamento da representação dos súditos e eliminando o arbítrio do rei.

As Revoluções do século XVIII e as declarações de direitos delas decorrentes continuaram este processo de consolidação dos direitos do homem.

A Declaração de Independência dos Estados Unidos, de 1776, consistiu no primeiro documento político a afirmar a existência de direitos inerentes a todo ser humano, independentemente de diferenças de raça, sexo, religião. Do texto da declaração podem-se verificar muitas influências jusnaturalistas, em destaque, Locke:

Consideramos as seguintes verdades como auto-evidentes, a saber, que todos os homens são criaturas iguais, dotadas pelo seu Criador de certos direitos inalienáveis, entre os quais a vida, a liberdade e a busca da felicidade.

É para assegurar esses direitos que os governos são instituídos entre os homens, sendo seus justos poderes derivados do consentimento dos governados.

Toda vez que alguma forma de governo torna-se nociva à consecução dessas finalidades, é direito do povo alterá-la ou aboli-la, e instituir uma nova forma de governo baseada nesses princípios, e cuja organização de poderes lhe pareça, segundo a maior probabilidade, capaz de proporcionar-lhe a segurança e a felicidade.

A Revolução Francesa, de 1789, é exemplo vivo que evidencia a cultura das

${ }^{8}$ COMPARATO, Fabio Konder. A afirmação histórica dos direitos humanos. 4. ed. São Paulo: Saraiva, 2005, p. 86. 
liberdades de tipo individualista e contratualista, ${ }^{9}$ de moldes nitidamente jusnaturalista. O artigo 2 da declaração dos direitos do homem e do cidadão deixa isto bastante claro: "O fim de toda associação política é a conservação dos direitos naturais e imprescindíveis do homem". A Lei, geral e abstrata, e o legislador, representante da vontade geral (ou seja, da naçã ${ }^{10}$ ), simbolizam a garantia da realização destes direitos.

Os revolucionários, por acreditarem - e estarem de fato - rompendo com toda uma lógica, a do antigo regime, acreditavam ser missionários de uma nova ordem que se pretendia universal. A Declaração de Direitos de 1789 afirmava tais direitos como universais. Como afirmou Mathiu de Montmorency "os direitos do homem em sociedade são eternos, [...] invariáveis como a justiça, eternos como a razão; eles são de todos os tempos e de todos os países". ${ }^{11}$

Acreditava-se, pois, ser uma declaração de todos os tempos e de todos os povos. A dupla menção, ao homem e ao cidadão, no título da Declaração pode ser explicada neste sentido, ou seja, a referência ao cidadão dirige-se ao povo francês, enquanto "homem", está simbolizando toda a humanidade, representada por todos os povos. $^{12}$

Percebe-se, com a filosofia jusnaturalista, que a afirmação dos direitos do homem foi contemporânea à consolidação dos Estados-Nação, ou melhor, do Estado de Direito. Na teoria esta interconexão ocorreu porque, muito embora houvesse a convicção da existência de direitos independentemente do reconhecimento deles por um ente (no caso este ente corresponde ao Estado, ao corpo político), o surgimento deste ente se deu pela necessidade de garantir tais direitos.

Na prática, por sua vez, o que ocorreu foi uma associação cada vez maior dos direitos dos homens com a afirmação da soberania nacional, fazendo do povo e não

9 FIORAVANTI, Maurizio. Los derechos fundamentales: apuentos de historia de las constituciones. Trad. Manuel Martinez Neira. Madrid: Trotta, 1996, p. 58.

${ }^{10}$ A idéia de nação também é fundamental para se entender o rompimento que a revolução estava realizando em relação ao antigo regime. A nação simboliza um corpo único, em reação à estrutura social medieval determinada e separada por estamentos.

${ }^{11}$ In COMPARATO, op. cit., p. 130.

${ }^{12}$ Ibid., p. 147. 


\section{A INSERÇÃO DA BIOPOLÍTICA NO DISCURSO DOS DIREITOS HUMANOS: A TRANSPOSIÇÃO DA VIDA DE DIREITO DO HOMEM INALIENÁVEL À OBJETO MATÁVEL}

mais do indivíduo o representante da imagem do homem. Ocorre, dessa maneira, uma crescente absorção dos direitos do homem pelos direitos do cidadão. Como afirma Fabio Konder Comparato: "os direitos do cidadão passaram, então, a servir de meios de proteção aos direitos do homem, e a vida política tornou-se mero instrumento de conservação da sociedade civil, sob a dominação da classe proprietária". ${ }^{13}$

A afirmação histórica dos direitos humanos, ou melhor, do discurso ocidental dos direitos humanos teve sua raiz filosófica no jusnaturalismo, a partir do qual o homem é dotado de direitos em decorrência da sua natureza humana. Todavia, na prática, o que ocorreu foi a consolidação do Estado e de seu direito positivo e a conseqüente afirmação dos direitos do homem em decorrência do que a lei do Estado expressamente determina. A positivação dos direitos acabou reduzindo a garantia destes não em decorrência da humanidade, mas da cidadania abstrata "vestida" pelo homem, empírico, concreto, de carne e osso.

Com a formação do Estado de Direito, a liberdade como poder original do sujeito foi substituída pela idéia de liberdades públicas, ou seja, a liberdade limitada pela lei. O direito subjetivo passa a ser distanciado da idéia de liberdade. Esta fragmentação torna-se nítida com a Declaração Universal dos Direitos do Homem e do Cidadão, em 1789: "O título da referida Declaração denuncia a fragmentação entre liberdade e direito subjetivo, representada nas categorias homem e cidadão". ${ }^{14}$

O poder, assim, é transferido para o Estado, na medida em que os homens detêm os direitos subjetivos desde que previstos pela ordem jurídica estatal.

Esta simultaneidade histórica entre a consolidação das nações-Estado e dos direitos humanos não foi por acaso e as conseqüências deste nexo, flagradas com os acontecimentos da primeira metade do século XX, foram nefastas à humanidade e demonstraram a fraqueza e falta de efetividade dos direitos do homem, apenas retoricamente declarados.

\footnotetext{
${ }^{13}$ Ibid., p. 143.

${ }^{14}$ GEDIEL, José Antônio Peres. Os transplantes de órgãos e a invenção moderna do corpo. Curitiba: Moinho do Verbo, 2000, p. 18.
} 


\title{
2 A INSERÇÃO DA BIOPOLÍTICA NA LÓGICA DOS DIREITOS HUMANOS
}

\subsection{BIOPOLÍTICA E A INSCRIÇÃO DA VIDA NATURAL NA ORDEM JURÍDICO-POLÍTICA}

\begin{abstract}
"A vida que, com as declarações dos direitos humanos tinha-se tornado o fundamento da soberania, torna-se agora o sujeito-objeto da política estatal (que se apresenta, portanto, sempre mais como polícia); mas somente um Estado fundado sobre a própria vida da nação podia identificar como sua vocação dominante a formação e tutela do corpo popular". ${ }^{15}$
\end{abstract}

Os séculos XVII e XVIII foram séculos em que a filosofia jusnaturalista afirmou a importância do homem, colocando-o como centro de todo o pensamento. Esta filosofia é responsável pela constituição do sujeito moderno, sujeito de direitos, autônomo e plenamente capacitado pela razão.

Cabe ressaltar que estes séculos corresponderam também a uma fase significativa do desenvolvimento capitalista, com a Revolução Industrial, ascensão econômica, social e política da burguesia. O sujeito moderno é, eminentemente, um sujeito proprietário. A idéia e a importância da propriedade desenvolveram-se juntamente com a idéia de liberdade e autonomia do homem, tomado este como um indivíduo dotado de direitos a ele inerentes (direitos subjetivos), com plena capacidade e autonomia para explorar e exercer todas as suas potencialidades.

Na realidade, os direitos subjetivos desenvolveram-se coerentes com a lógica patrimonial capitalista-burguesa do liberalismo econômico. A universalidade e a abstração do homem moderno, afirmadas pelo jusnaturalismo acabaram servindo de instrumento para a lógica de reprodução capitalista.

Neste sentido afirma Michel Miaille: "Não é natural que todos os homens sejam sujeitos de direito. Isto é o efeito de uma estrutura social bem determinada: a

${ }^{15}$ AGAMBEN, Giorgio. Homo sacer: poder soberano e a vida nua. Trad. Henrique Burigo. Belo Horizonte: UFMG, 2002. v. 1, p. 155. 


\section{A INSERÇÃO DA BIOPOLÍTICA NO DISCURSO DOS DIREITOS HUMANOS: A TRANSPOSIÇÃO DA VIDA DE DIREITO DO HOMEM INALIENÁVEL À OBJETO MATÁVEL}

sociedade capitalista. Mas, então, porque é que isso é necessário nesta sociedade? Precisamente para permitir a realização das trocas mercantis generalizadas". ${ }^{16}$ Com este posicionamento, o autor demonstra claramente que o sujeito de direitos não passou, ou melhor, não passa de uma noção histórica, tendo surgido precisamente no momento histórico concernente ao capitalismo.

Michel Foucault, crítico ferrenho do processo histórico da modernidade, observando este sujeito moderno, inserido na lógica burguesa capitalista e no progresso científico, constatou um sujeito construído não apenas pela idéia de emancipação (cujo instrumento era a razão), mas por mecanismos a ele externos, que não deixavam de carregar em si uma certa racionalidade.

Como bem observou Foucault, o sujeito moderno autônomo e dono de si sofreu muitas pressões e golpes do sistema capitalista. A autonomia foi forjada pela lógica do capital. A abstração do sujeito de direitos, dotado de poderes, a igualdade formal e a liberdade eram inquestionáveis enquanto serviam de instrumentos para circulação de riquezas e formulação de contratos

Foucault rompe, então, com a concepção transcendental e universal do sujeito, partindo da idéia de que o sujeito é constituído pela história a todo o momento. E a história do desenvolvimento do capitalismo constituiu um sujeito bastante útil para funcionar nas engrenagens do seu sistema.

Foucault analisa, então, um sujeito constituído por mecanismos de poder compatíveis com o funcionamento do sistema do capitalismo. Obviamente que o autor não ignora o poder soberano do Estado e a relação deste com seus súditos, mas afirma a existência destes outros poderes disseminados na sociedade e, posteriormente, apreendidos também pelo Estado, e que atuam no sujeito e na constituição de sua subjetividade de forma incisiva.

O sujeito, em sua corporalidade e vida, tornou-se objeto de poderes. Estes

\footnotetext{
${ }^{16}$ MIAILLE, Michel. Introdução crítica ao direito. 2. ed. Lisboa: Estampa, 1989, p. 117.
} 
poderes, para Foucault, são o poder disciplinar ${ }^{17}$ e a biopolítica.

O poder disciplinar atua individualmente sobre o corpo do sujeito classificando-o, examinando-o, de modo a aumentar sua força útil pelo exercício e treinamento. A biopolítica corresponde a um outro poder normalizador (não menos voltado ao controle) que terá como campo de incidência as populações, a espécie humana, a vida do homem.

É curioso notar que tanto a criação do conceito de indivíduo quanto a criação do conceito de população são criações políticas. Como já visto, o conceito de indivíduo nasce juntamente com o conceito de cidadão no sentido moderno da ótica contratualista:

L'idea dell'individuo è politicamente legata alla costruzione laica della figura del cittadino che se aferma con la formazione degli Stati-nazione moderni. L'individuo non ̀̀ l'espressione di una singolarità che si opporrebbe a tutte le figure della quantità indistinta massa, popolo, classe, partito -; al, contrario, viene prodoto insieme, fa parte della stessa gramatica política, dalla stessa strutturazione logica del mondo: appartiene alla formulazione del potere moderno. ${ }^{18}$

Esta forma de poder (biopolítica) aparece a partir da segunda metade do século

${ }^{17}$ A disciplina toma os sujeitos como objetos, adestrando-os e fabricando-os. Ela opera basicamente por três mecanismos: a vigilância; a sanção normalizadora e o exame. A vigilância é o componente fundamental para o funcionamento das instituições modernas (escolas, hospitais, fábricas, quartéis, prisões), locais onde o poder disciplinar se materializa. O modelo desta vigilância disciplinar será a figura do panóptico, configurando, assim, uma sociedade de disciplina e controle. A segunda dimensão da disciplina, a sanção normalizadora, direciona-se para o estabelecimento de uma ordem, artificialmente construída, por meio de castigos e punições, similares ao modelo jurídico. A punição disciplinar oscilará entre o castigo e o prêmio, fixando-se assim padrões e modelos de comportamento. Por fim há o exame, o mais ritualizado dos dispositivos da disciplina. Nele se combina a formação de um saber e um exercício de poder. Por este instrumento os indivíduos são documentados, registrados, são passíveis de análise e descrição, tornando-se objetos - objetos do exame. Os indivíduos são caracterizados de acordo com determinados fenômenos, estando ligados pela norma aos traços, padrões e medidas que determinam a normalidade e o desvio. O exame corresponde, então, ao mecanismo que possibilita um sistema de descrição do comportamento dos sujeitos. O exame será a forma de saber-poder que dará lugar às ciências humanas, como a Psicologia e a Sociologia.

18 "A idéia de indivíduo é politicamente legada à construção laica da figura do cidadão que se afirma com a formação dos Estados-Nação modernos. O indivíduo não é expressão de uma singularidade que se oporia à toda figura de qualidade indistinta - massa, povo, classe, partido -; ao contrário, vem produzida em conjunto, faz parte da mesma gramática política, da mesma estruturação lógica do mundo: pertence à formulação do poder moderno." (REVEL, Judith. Michel Foucault: 


\section{A INSERÇÃO DA BIOPOLÍTICA NO DISCURSO DOS DIREITOS HUMANOS: A TRANSPOSIÇÃO DA VIDA DE DIREITO DO HOMEM INALIENÁVEL À OBJETO MATÁVEL}

XVIII, contemporânea à afirmação do liberalismo econômico. ${ }^{19} \mathrm{O}$ biopoder não anulará ou substituirá a disciplina, mas a ela se integrará, utilizando-a e modificando-a parcialmente. Aplicar-se-á "[...] não ao homem corpo, mas ao homem vivo, ao homem ser vivo [...] ao homem espécie". ${ }^{20}$

Por ser um poder que corresponde a uma crescente implicação da vida natural do homem nos mecanismos de poder, ${ }^{21}$ a biopolítica se dirige a questões ligadas à espécie como natalidade, mortalidade, fecundidade, longevidade, saúde pública enfim, os problemas econômicos e políticos das "massas" tornam-se objetos de controle. Trata-se de gerir a vida de quem faz parte da força de trabalho.

A vida do homem tornou-se uma questão política - política e vida na modernidade entram numa verdadeira simbiose, a ponto da distinção público e privado perderem real significado - a vida inteira torna-se objeto de poder. Neste sentido:

Sulla distinzione tra pubblico e privato, bisogna spendere due parole: la vicenda ̀̀ complessa perché da una parte i rapporti di potere, diventano poteri sulla vita, annullano la distinzione pubblico/privato; in effetti [...] i raporti di potere devono intervenire non solo sulla gestione diretta del tempo e del luogo di lavoro, ma su uma dimensione che non è solo privata ma anche intima della vita dei soggetti: sulla loro sessualità, sulla riproduzione, sull'alimentazione, sui ritmi e i tempi della vita, sull'igiene: tutto questo diventa oggeto di misure, leggi e gestione pubblica. ${ }^{22}$

A distinção público e privado acaba existindo, mas por uma criação puramente artificial do liberalismo e sua razão de governar (ou melhor, "pouco governar").

un’ontologia dell'atualità. Calabria: Rubenttino, 2003, p. 96)

${ }^{19}$ FOUCAULT, Michel. Resumo dos cursos do Collège de France. Trad. Andréa Daher. Rio de Janeiro: Zahar, 1997.

${ }^{20}$ FOUCAULT, Michel. Em defesa da sociedade. São Paulo: Martins Fontes, 2002, p. 289.

${ }^{21}$ AGAMBEN, op. cit., p. 126.

22 "Sobre a distinção entre público e privado, é preciso gastar duas palavras: o evento é complexo porque de uma parte as relações de poder, tornam-se poderes sobre a vida, anulam as distinções público/privado; de efeito, as relações de poder devem intervir não somente sobre a gestão direta do tempo e do lugar de trabalho, mas sobre uma dimensão que não é somente privada mas também íntima da vida dos sujeitos: sobre sua sexualidade, sobre reprodução, sobre alimentação, sobre ritmos e tempos de vida, sobre higiene: tudo isto torna-se objeto de medida, leis e gestão pública." (REVEL, op. cit., p. 125). 
Foucault, em sua análise sobre a biopolítica, permite que se perceba uma mudança nas concepções a respeito dos direitos de vida e de morte, característicos da teoria clássica da soberania. Muitos autores jusnaturalistas, entre eles Jean-Jaques Rousseau, eram a favor da pena de morte e defendiam a alienação de todos os direitos ao Estado, inclusive o direito à vida. Nas palavras de Rousseau:

[...] o cidadão não é mais juiz do perigo ao qual a lei quer que se exponha e, quando o príncipe lhe diz: 'É útil ao Estado que morras', deve morrer, pois foi exatamente por essa condição que até então viveu em segurança e que sua vida não é mais mera dádiva da natureza, porém um dom condicional do Estado. A pena de morte infligida aos criminosos pode ser considerada, aproximadamente, do mesmo ponto de vista [...]. ${ }^{23}$

O soberano, neste sentido, tem direito de vida e de morte, o que para Foucault significa, no fundo, que ele pode fazer morrer e deixar viver. Assim, a vida e a morte não seriam meros fenômenos naturais, fora do campo político. Nas palavras de Foucault "[...] em relação ao poder, o súdito não é, de pleno direito, nem vivo, nem morto. Em todo caso, a vida e a morte dos súditos só se tornam direitos pelo efeito da vontade do soberano". ${ }^{24}$

Segundo Foucault, então, este "direito" da soberania, com as transformações políticas do século XIX, será complementado por um outro direito, que irá perpassá-lo e modificá-lo: o direito de fazer viver e deixar morrer. Este novo direito se instalará em função das técnicas de poder da disciplina, mas, principalmente, da biopolítica.

A supervalorização da vida será uma decorrência da lógica deste novo mecanismo de poder, que é exatamente a biopolítica.

À cada conquista, à cada espaço de direito e de liberdade alcançados pelos indivíduos, estes simultaneamente inscrevem cada vez mais suas vidas na ordem estatal, oferecendo mais poder ao poder soberano do qual queria se libertar. ${ }^{25}$ Como

\footnotetext{
${ }^{23}$ ROUSSEAU, Jean-Jaques . O contrato social. São Paulo: Victor Civita, 1983. l. 2, p. 52.

${ }^{24}$ FOUCAULT, Michel. Em defesa da sociedade..., p. 286.

${ }^{25}$ AGAMBEN, op. cit., p. 127.
} 


\section{A INSERÇÃO DA BIOPOLÍTICA NO DISCURSO DOS DIREITOS HUMANOS: A TRANSPOSIÇÃO DA VIDA DE DIREITO DO HOMEM INALIENÁVEL À OBJETO MATÁVEL}

afirma Foucault:

O direito à vida, ao corpo, à saúde, à felicidade, à satisfação das necessidades, o direito, acima de todas as opressões e alienações, de encontrar o que se é e tudo o que se pode ser, esse direito tão incompreensível para o sistema jurídico clássico, foi a réplica política de todos esses novos procedimentos de poder que, por sua vez, também não fazem parte do direito tradicional da soberania. ${ }^{26}$

A bipolítica procura "[...] levar em conta a vida, os processos biológicos do homem-espécie e de assegurar sobre eles não uma disciplina, mas uma regulamentação". ${ }^{27}$

A sociedade de normalização é aquela em que a norma da disciplina e a norma da biopolítica se cruzam, influenciando nas vidas e nas subjetividades dos indivíduos. A própria lei passa a funcionar mais como "norma", e a instituição jurídica se integra cada vez mais aos aparelhos e mecanismos médicos e administrativos de funções essencialmente reguladoras. Como denuncia Foucault: "[...] as Constituições escritas no mundo inteiro a partir da Revolução Francesa, os códigos redigidos e reformados, toda uma atividade legislativa permanente e ruidosa não devem iludir-nos: são formas que tornam aceitável um poder essencialmente normalizador". ${ }^{28}$

Agamben expõe que o primeiro grande registro da vida como objeto de poder corresponde ao Habeas Corpus. Tem-se, neste documento, não só a afirmação do direito de liberdade, mas a visualização que a liberdade que se afirmava, a moderna, correspondia à liberdade do corpo - novo sujeito da política e objeto de poder: "Se é verdade que a lei necessita, para a sua vigência, de um corpo, se é possível falar, neste sentido, do desejo da lei de ter um corpo, a democracia responde ao seu desejo obrigando a lei a tomar sob seus cuidados este corpo". ${ }^{29}$

${ }^{26}$ FOUCAULT, Michel. História da sexualidade. 15. ed. Trad. Maria Thereza da Costa Albuquerque e J. A. Guilhon Albuquerque. Rio de Janeiro: Graal, 1998. v. 1: a vontade de saber, p. 136.

\footnotetext{
${ }^{27}$ FOUCAULT, Michel. Em defesa da sociedade... p. 293-294.

${ }^{28}$ FOUCAULT, Michel. História da sexualidade..., p. 135-136.

${ }^{29}$ AGAMBEN, op. cit., p. 130.
} 
Ainda, este autor concebe, nas declarações dos direitos, a figura original da inscrição da vida natural do homem, antes, no antigo regime, politicamente indiferente, na ordem jurídico-política do Estado-Nação tornando-se o fundamento terreno da sua legitimidade e soberania. ${ }^{30}$

Para ele as declarações dos direitos devem ser vistas como a passagem da soberania divina para a soberania nacional. Ao analisar o texto da declaração de 1789, evidencia que o mero nascimento já inscreve o homem na comunidade política, dissipando-o na figura do cidadão. O nascimento que antes dava origem apenas ao súdito passa a constituir o fenômeno que integra o homem e sua vida no corpo político, conformando-o ao sujeito soberano. O nascimento integra-o à nação, e não mais apenas homem, mas cidadão o indivíduo passa a ser. Nas palavras de Agamben: "Os direitos são atribuídos ao homem (ou brotam dele), somente na medida em que ele é o fundamento, imediatamente dissipante (e que, aliás, não deve nunca vir à luz como tal), do cidadão". ${ }^{31}$

\section{A REDUÇÃO DOS DIREITOS HUMANOS AOS DIREITOS DO CIDADÃO: DE CIDADÃO À VIDA NUA}

A inscrição da vida do homem na seara política, por meio do reconhecimento de que pelo nascimento este homem se torna já um cidadão, acabou misturando as figuras homem e cidadão, e a segurança e a garantia dos direitos viram-se vinculadas à figura do cidadão, na medida em que a vida natural foi totalmente incluída na pólis.

Para Agamben, "uma das características essenciais da biopolítica moderna (que chegará, no nosso século, século XX, à exasperação) é a sua necessidade de redefinir continuamente, na vida, o limiar que articula e separa aquilo que está dentro

\footnotetext{
${ }^{30}$ Ibid., p. 134.

${ }^{31}$ Ibid., p. 135.
} 


\section{A INSERÇÃO DA BIOPOLÍTICA NO DISCURSO DOS DIREITOS HUMANOS: A TRANSPOSIÇÃO DA VIDA DE DIREITO DO HOMEM INALIENÁVEL À OBJETO MATÁVEL}

daquilo que está fora". ${ }^{32} \mathrm{O}$ cidadão é aquilo que está dentro. O que, então, restará fora?

O pós Primeira Guerra mundial e o sistema geopolítico europeu mostraram, na figura dos refugiados e apátridas, o paradoxo dos direitos humanos, pois demonstraram que "No sistema do Estado-nação, os ditos direitos sagrados e inalienáveis do homem mostram-se desprovidos de qualquer tutela e de qualquer realidade no mesmo instante em que não seja possível configurá-los como direitos dos cidadãos de um Estado". 33

Como expõe Hannah Arendt, significativos grupos humanos migratórios que deixavam seus Estados e se tornavam apátridas, nos anos que seguiram a primeira grande guerra, permaneceram sem lar e foram despossuídos de todos os seus direitos, até então tidos e definidos como inalienáveis. A perda de um governo que os representasse e os protegesse significou a perda dos seus direitos humanos. Assim, estes apátridas encontravam-se numa situação de absoluta ausência de lei. ${ }^{34}$

Esta situação tornou-se uma poderosa arma nas mãos dos governos totalitários, que através de medidas de desnacionalização, enfraqueciam cada vez mais qualquer discurso de defesa dos direitos humanos. Nas palavras de Hannah Arendt: "A expressão 'direitos humanos' tornou-se para todos os interessados - vítimas, opressores e espectadores - uma prova de idealismo fútil ou de tonta e leviana hipocrisia". ${ }^{35}$ E ainda: "Somos quase tentados a medir o grau de infecção totalitária de um governo pelo grau em que usa o seu soberano direito de desnacionalização". ${ }^{36}$

Neste terreno nascem e se disseminam os movimentos fascistas e nazistas, dois movimentos biopolíticos em sentido próprio, ${ }^{37}$ como afirma Agamben. ${ }^{38}$

${ }^{32}$ Ibid., p. 136.

${ }^{33}$ Ibid., p. 133.

34 ARENDT, Hannah. As origens do totalitarismo. Trad. Roberto Raposo. São Paulo: Companhia das Letras, 1989.

${ }^{35}$ Ibid., p. 302.

${ }^{36}$ Ibid., p. 312.

${ }^{37}$ Foucault deixa muito clara a natureza biopolítica destes movimentos em seu livro "Em defesa da sociedade". A princípio parece absurdo vincular movimentos que disseminaram uma lógica de matança a um poder que supervaloriza a vida, como é a biopolítica. A justificativa deste vínculo 
Algumas leis, como a de Nuremberg sobre a cidadania do Reich, chegaram a dividir a cidadania em graus: cidadão a título pleno e cidadão de segundo escalão aqueles, que obviamente, por serem inferiores deveriam gozar de menos direitos. A partir exatamente desta lógica que os judeus eram encaminhados aos campos de extermínio: reduzia-se gradativamente a sua cidadania até que se tornassem vidas nuas, totalmente passíveis de serem exterminadas. Criava-se uma situação de privação total de direitos, para enfim reduzi-los à vida nua, pois, uma vez que o homem portador daquela vida deixou de ser um sujeito de direitos, a sua vida deixou de ser um direito, um bem jurídico, tornando-se, então, em vida matável, cujo extermínio não acarreta conseqüências jurídicas. Como afirma Agamben: "[...] os Estados-nação operam um maciço reinvestimento da vida natural, discriminando em seu interior uma vida por assim dizer autêntica e uma vida nua privada de todo valor político [...]". 39

Agamben afirma que a continuidade entre nascimento e nação é rompida com a figura dos refugiados. Estes passam a ser, como afirma Hannah Arendt, o homem dos direitos sem a máscara do cidadão, o que significava, na prática, ausência de direitos, na medida em que a perda dos direitos nacionais representava a perda dos direitos humanos. Segundo a autora: "Nenhum paradoxo da política contemporânea é tão dolorosamente irônico como a discrepância entre os esforços de idealistas bemintencionados, que persistem teimosamente em considerar 'inalienávies' os direitos desfrutados pelos cidadãos dos países civilizados, e a situação de seres humanos sem

está justamente na essência destes dois movimentos: o racismo. O racismo se insere na lógica do Estado para permitir que dentro de sistema que se assegura e se valoriza a vida se possa matar. Este racismo legitima o poder de morte do Estado. Como afirma Foucault, o racismo exerce um corte entre o que deve viver e o que deve morrer. Subdivide-se a espécie em raças - fragmenta-se o contínuo biológico. O matar torna-se, pelo viés do racismo, compatível com o biopoder. Nasce uma relação biológica e guerreira entre a vida e a morte: $\mathrm{O}$ inimigo não é mais no sentido político, mas no sentido biológico, de raça inferior, que simboliza um perigo à raça superior.

Por tirar a vida, Foucault é bem claro que não entende ser apenas o assassino direto, mas formas indiretas como a rejeição, a exclusão, a exposição à morte.Com o racismo ocorre novamente a justaposição do direito soberano do Estado de fazer morrer e deixar viver, com o direito de fazer viver e deixar morrer.O nazismo e o fascismo são exemplos nítidos desta justaposição. (FOUCAULT, Michel. Em defesa da sociedade..., op. cit.)

\footnotetext{
${ }^{38}$ AGAMBEN, op. cit., p. 135.

${ }^{39}$ Ibid., p. 139.
} 


\section{A INSERÇÃO DA BIOPOLÍTICA NO DISCURSO DOS DIREITOS HUMANOS: A TRANSPOSIÇÃO DA VIDA DE DIREITO DO HOMEM INALIENÁVEL À OBJETO MATÁVEL}

direito algum". ${ }^{40}$

Para Hannah Arendt, num mundo como o do século XX, organizado politicamente, a perda do status civil significa ser expulso da humanidade, pois de nada valem os direitos humanos quando se está fora da trindade Estado-PovoTerritório. $^{41}$

Os indivíduos sem Estado, os apátridas, tornaram-se "fora da lei" e uma vez ausente a lei, deles eram destituídos todos os direitos. Sem seus direitos reconhecidos viviam em constante transgressão à lei. Como expõe Hannah Arendt, melhor do que uma anomalia não prevista pela lei preferia-se enquadrar numa anomalia por ela prevista, ou seja, o criminoso.

A autora demonstra que, a situação dos apátridas em relação à proteção de seus direitos era tão precária, que o fato de cometer um crime tornava sua posição legal melhor - o crime passa a ser um instrumento de recuperação de uma certa igualdade humana: "Só como transgressor da lei pode o apátrida ser protegido pela lei. Enquanto durem o julgamento e pronunciamento da sua sentença, estará a salvo daquele domínio arbitrário da polícia, contra a qual não existem advogados e apelações". ${ }^{42}$

Toda esta triste realidade mostrou que o fundamento dos direitos humanos, ou seja, a própria natureza humana, afirmado pela filosofia jusnaturalista a partir da qual se basearam as declarações dos direitos, perdeu-se ao longo dos acontecimentos históricos, principalmente da primeira metade do século XX. Os refugiados e apátridas foram prova viva de que o mero fato de ser homem - "a nudez abstrata de serem unicamente humanos"43 - não é garantia de direitos, na medida em que tornaram-se vidas totalmente supérfluas. A vida nua desprovida da vestimenta de cidadania e

${ }^{40}$ ARENDT, op. cit., p. 314.

${ }^{41}$ In LAFER, Celso. A reconstrução dos direitos humanos: um diálogo com o pensamento de Hannah Arendt. São Paulo: Companhia das Letras, 1988, p. 147.

${ }^{42}$ Ibid., p. 320.

${ }^{43}$ Ibid., p. 333. 
banida da nação tornou-se, de direito inalienável a objeto matável.

Como afirma Hannah Arendt, assim como o homem do século XVIII desprendeu-se da história, o homem do século XX emancipou-se da natureza. A essência do homem deixou de ser compreendida por ambas. "Esta nova situação, na qual a humanidade assumiu de fato um papel antes atribuído à natureza ou à história, significaria nesse contexto que o direito de ter direitos, ou o direito de cada indivíduo de pertencer à humanidade, deveria ser garantido pela própria humanidade". ${ }^{44}$

\title{
CONCLUSÃO
}

\begin{abstract}
"O homem, durante milênios, permaneceu o que era para Aristóteles: um animal vivo e, além disso, capaz de existência política; o homem moderno é um animal, em cuja política, sua vida de ser vivo está em questão". ${ }^{4}$
\end{abstract}

A excessiva politização da vida, conseqüência da biopolítica, tornou a vida um objeto manipulável. Na medida em que é politicamente relevante, esta vida recebe proteção do poder soberano do Estado, que envolve o ser vivente numa camada protetora intitulada cidadania - enquanto cidadão a vida do homem é protegida. Quando não mais convém - e o que convém passou a ser determinado pelo racismo de Estado - esta vida deixa de ter relevância política. O mesmo Estado que reconhece direitos, simplesmente deixa de reconhecê-los, retira a máscara do cidadão e escancara a nudez da vida, tornando qualquer ato ou atentado contra ela não mais homicídio, mas um ato qualquer, não mais gerador de efeitos jurídicos, por sua artificial irrelevância política - a vida torna-se matável.

A afirmação dos direitos humanos, a consolidação dos Estados-Nação, e a

\footnotetext{
${ }^{44}$ Ibid., p. 332.

${ }^{45}$ FOUCAULT, Michel. História da sexualidade ..., p. 134.
} 


\section{A INSERÇÃO DA BIOPOLÍTICA NO DISCURSO DOS DIREITOS HUMANOS: A TRANSPOSIÇÃO DA VIDA DE DIREITO DO HOMEM INALIENÁVEL À OBJETO MATÁVEL}

inserção da biopolítica como forma de governar e gerir a vida, tornando-a objeto de poder - três processos que ocorreram de maneira simultânea - são responsáveis pelo retrato paradoxal da realidade contemporânea ocidental.

O panorama jurídico em que a vida se encontra atualmente não deixa de mostrar este paradoxo. Muito embora a pena de morte tenha sido abolida do campo normativo da maioria dos países ocidentais, ela não foi completamente abolida. Não obstante, a própria abolição, como afirma Foucault não decorreu apenas de sentimentos humanitários, mas ocorreu também em razão da inserção de um poder cuja lógica e função era de gerir a vida. Nas palavras de Foucault:

Para um poder deste tipo, a pena capital é, ao mesmo tempo, o limite, o escândalo e a contradição. Daí o fato de que não se pode mantê-la a não ser invocando, nem tanto a enormidade do crime quanto a monstruosidade do criminoso, sua incorrigibilidade e a salvaguarda da sociedade. São mortos legitimamente aqueles que constituem uma espécie de perigo biológico para os outros. ${ }^{46}$

A pena de morte que ainda existe em alguns estados dos Estados Unidos, país que se diz democrático e liberal, é um exemplo de como a vida tida como um direito pode ser objeto manipulável, na medida em que a morte de um criminoso deixa de ser um homicídio. A abstração jurídica do que vem a ser ou não homicídio, e, conseqüentemente, a vida que é ou não é mais reconhecida como um bem jurídico (e, portanto, politicamente relevante) demonstra o quanto o sujeito moderno tornou-se objeto de poder - sublimou-se o sujeito numa abstração universal, para poder manipular o momento em que este sujeito pode voltar à sua concretude puramente biológica, e tornar-se novamente um ser matável, destituído de direitos e liberdades. "Condenados à morte [...] são, portanto, de algum modo assemelhados [...] a uma vida que pode ser morta sem que se cometa homicídio. $\mathrm{O}$ intervalo entre a condenação à morte e a execução [...] delimita um limiar extratemporal e extraterritorial, no qual o corpo humano é desligado de estatuto político normal e, em estado de exceção, é

\footnotetext{
${ }^{46}$ Ibid., p. 130.
} 
abandonado às mais extremas peripécias". ${ }^{47}$

Nada impede dizermos que a própria resistência à legalização da eutanásia também decorre desta lógica biopolítica de proteção e supervalorização da vida. O Estado assumiu a proteção do direito à vida de seus cidadãos a ponto de proibir qualquer atentado em relação a este bem, ainda que decorrente do próprio consentimento do ser vivente em questão. No momento em que, como demonstrou Agamben, a vida se inseriu na ordem jurídico-política, a esfera de autonomia do sujeito e a disponibilidade da sua vida nua foram reduzidas e substituídas pelo poder de decisão do Estado que, ao circunscrever esta vida, tornou-a politicamente e juridicamente relevante.

Percebe-se, então, como o "direito à vida" não foi apenas juridicamente protegido em nome da proteção do homem, como um direito natural e inalienável (até porque os próprios jusnaturalistas não defendiam a incondicionalidade do direito à vida, na medida em que eram a favor da pena de morte em alguns casos), mas a exaltação da vida como um bem jurídico absoluto acompanhou um processo histórico transpassado por uma teia de interesses e poderes que o Estado e sua razão de governar, atribuindo a criação normativa para si e adotando mecanismos e técnicas biopolíticas, infringiu sobre o sujeito. Proteger a vida e o corpo passou a significar ter sob o controle um objeto de poder.

Os casos de tortura realizados por soldados americanos em supostos membros de organizações terroristas, divulgados pela imprensa mundial, demonstraram a nudez da vida e dos corpos humanos. A prática de tais atos justifica-se exatamente pelo paradoxo do estado de exceção que hoje se tornou regra - num estado de direito, como se auto-intitulam os Estados Unidos, a tortura teoricamente não permitida grita nos corredores das prisões americanas distantes de seu território democrático. As manobras jurídicas que permitem e justificam tais atos chegam ao absurdo de tentar redefinir a tortura - esta corresponderia "ao equivalente em intensidade à dor que acompanha danos físicos graves, como falência de órgãos ou de funções corporais ou

\footnotetext{
${ }^{47}$ AGAMBEN, op. cit., p. 166.
} 


\section{A INSERÇÃO DA BIOPOLÍTICA NO DISCURSO DOS DIREITOS HUMANOS: A TRANSPOSIÇÃO DA VIDA DE DIREITO DO HOMEM INALIENÁVEL À OBJETO MATÁVEL}

até a morte". ${ }^{48}$

Será que a gravidade dos atos cometidos por terroristas justificam a banalização da humanidade a este extremo? Não se trata exatamente de defender a humanidade, que se luta hoje contra o terrorismo? A vida de um homem tem exatamente o mesmo valor da vida de muitos e de toda a humanidade, pois esta está presente em um homem e em todos os homens ao mesmo tempo.

A natureza humana deixou de ser fundamento de qualquer direito, inclusive o direito à vida, no momento em que o simples fato de ser homem nada garante, nada protege. Os direitos humanos perdem a sua eficácia quando estão vinculados apenas a um ser humano. Como afirma Hannah Arendt:

O paradoxo da perda dos direitos humanos é que essa perda coincide com o instante em que a pessoa se torna um ser humano em geral - sem uma profissão, sem uma cidadania, sem uma opinião, sem uma ação pela qual se identifique e se especifique - e diferente em geral, representado nada além da sua individualidade absoluta e singular, que privada da expressão e da ação sobre um mundo comum, perde todo seu significado. ${ }^{49}$

Não cabe a este artigo afirmar a perda da natureza humana como fundamento, como algo que se deve lamentar e, por esta razão, de alguma maneira, "rebuscá-lo", até porque, poder-se-ia afirmar uma verdadeira, universal e atemporal natureza humana?

Seguindo o pensamento de Norberto Bobbio e tantos outros, a raiz do problema hoje não está na busca de um fundamento único. Como Bobbio mesmo afirma "Não se concebe como seja possível atribuir um fundamento absoluto a direitos historicamente relativos". 50

O que hoje deve nortear aqueles que estiverem preocupados com a humanidade e a perpetuação do imperativo kantiano de que a humanidade deve ser

${ }^{48}$ Conteúdo referente a um parecer elaborado por Alberto R. Gonzáles, consultor jurídico do Departamento de Defesa dos Estados Unidos, in Revista Veja de 23 de jul. 2004, p. 88.

49 ARENDT, Hannah. As origens do totalitarismo. Trad. Roberto Raposo. São Paulo: Companhia das Letras, 1989, p. 336.

${ }^{50}$ BOBBIO, op. cit., p. 19. 
sempre o fim e nunca o meio, é a busca pelo reconhecimento dos direitos e liberdades do sujeito em sua concretude e especificidade, cuja generalidade e abstração do pensamento moderno fez perder o significado, como afirmou Hannah Arendt. ${ }^{51}$

Sabe-se que a teoria dos direitos humanos tem uma forte carga ideológia. Como afirma Elio Gallego: "[...] los derechos humanos no sólo actúan como legitimadores o desligitimadores de realidades sociales y políticas, sino también como proyecto que me atevería a calificar de cuasi-religioso, como plasmación de un ideal que cabría denominar como la 'religion del hombre'".52

Desmistificar a generalidade, abstração e universalidade do discurso moderno, pretensioso e arrogante, e atentar para a historicidade de cada acontecimento são as chaves da compreensão da realidade paradoxal dos direitos humanos estruturada por um processo igualmente paradoxal que foi a Modernidade.

Pensar os direitos dos homens livres da nossa arrogância moderna é o primeiro passo.

\section{REFERÊNCIAS}

AGAMBEN, Giorgio. Homo sacer: poder soberano e a vida nua. Trad. Henrique Burigo. Belo Horizonte: UFMG, 2002. v. 1.

ARENDT, Hannah. As origens do totalitarismo. Trad. Roberto Raposo. São Paulo: Companhia das Letras, 1989.

${ }^{51}$ A própria Hannah Arendt já afirmava que os direitos humanos não são algo dado, mas sim algo construído historicamente - correspondem a uma invenção que depende da cidadania para serem efetivados. Para a autora o primeiro direito humano é o direito a ter direitos, e isto só ocorre quando o homem faz parte de uma comunidade organizada, onde há trocas de ações e opiniões. O direito a fazer parte da polis, da vida pública é para ela o direito humano fundamental e primeiro.

52 "[...] os direitos humanos não só atuam como legitimadores ou desligitimadores de realidade sociais e políticas, senão também como projeto que me atreveria a qualificar de quasereligioso, como plasmação de um ideal que caberia denominar como a 'religião' do homem" (GALLEGO, Elio. Tradición jurídica y derecho subjetivo. Madrid: Dykinson, 1996, p. 141). 
BOBBIO, Norberto. A era dos direitos. Trad. Carlos Nelson Coutinho. Rio de Janeiro: Campus, 1992.

COMPARATO, Fabio Konder. A afirmação histórica dos direitos humanos. 4. ed. São Paulo: Saraiva, 2005.

FIORAVANTI, Maurizio. Los derechos fundamentales: apuentos de historia de las constituciones. Trad. Manuel Martinez Neira. Madrid: Trotta, 1996.

FOUCAULT, Michel. História da sexualidade. 15. ed. Trad. Matia Thereza da costa Albuquerque e J. A. Guilhon Albuquerque. Rio de Janeiro: Graal, 1998. v. 1: a vontade de saber.

Zahar, 1997.

Resumo dos cursos do Collège de France. Trad. Andréa Daher. Rio de Janeiro: . Em defesa da sociedade. São Paulo: Martins Fontes, 2002.

GALLEGO, Elio. Tradición jurídica y derecho subjetivo. Madrid: Dykinson, 1996.

GEDIEL, José Antônio Peres. Os transplantes de órgãos e a invenção moderna do corpo. Curitiba: Moinho do Verbo, 2000.

LAFER, Celso. A reconstrução dos direitos humanos: um diálogo com o pensamento de Hannah Arendt. São Paulo: Companhia das Letras, 1988.

LOCKE, John. Segundo tratado sobre o governo civil: ensaio sobre a origem, os limites e os fins verdadeiros do governo civil. 3. ed. Rio de Janeiro: Vozes, 1994.

MIAILLE, Michel. Introdução crítica ao direito. 2. ed. Lisboa: Estampa, 1989.

REVEL, Judith. Michel Foucault: un’ontologia dell'atualità. Calabria: Rubenttino, 2003.

REVISTA VEJA, São Paulo, 23 jul. 2004.

ROUSSEAU, Jean-Jaques. O contrato social. São Paulo: Victor Civita, 1983. l. 2. (Coleção Os Pensadores). 